\title{
A REPRESENTAÇÃO DA AVIFAUNA DA ÁREA DE PROTEÇÃO AMBIENTAL DO PRATIGI NA COLEÇÃO DE AVES DO MUSEU DE ZOOLOGIA DA UNIVERSIDADE ESTADUAL DE FEIRA DE SANTANA, BAHIA. \\ Carolina Figuerêdo Costa- e Caio Graco Machado ${ }^{2}$ \\ 1. Bolsista PROBIC/UEFS, Graduanda em Bacharelado em Ciências Biológicas, Universidade Estadual de Feira de Santana, e-mail: carolinafigueredc@gmail.com \\ 2. Orientador, Departamento de Ciências Biológicas - DCBio, Universidade Estadual de Feira de Santana, e-mail: gracom@uol.com.br
}

PALAVRAS-CHAVE: coleção ornitológica; inventariado; Mata Atlântica.

\section{INTRODUÇÃO}

O conhecimento da diversidade de aves brasileiras começou muito tardiamente, sendo este país um dos últimos das Américas a ter a sua natureza explorada de maneira mais consistente e organizada. As restrições impostas pela Coroa Portuguesa à entrada de pesquisadores estrangeiros no Brasil só foram relaxadas a partir da fuga da família real para o Rio de Janeiro, no começo do século XIX (Silveira \& Olmos, 2007). O surgimento de procedimentos para a manutenção de espécimes com finalidades científicas ou mesmo puramente expositivas, iniciou-se apenas no Século 19 (Silveira \& Olmos, 2007).

Coleções ornitológicas sempre foram centros de produção e difusão do conhecimento básico sobre a diversidade e distribuição de aves no Brasil, país que se destaca no cenário mundial como um dos de maior riqueza ornitológica, rivalizando apenas com a Colômbia e o Peru (CBRO 2007).

Além de contribuir para a formação de alunos de graduação e pós-graduação, as coleções de aves brasileiras têm contribuído para o aprimoramento da qualidade do ensino fundamental e médio de ciências biológicas e educação ambiental em todo o país. O fortalecimento e ampliação das coleções de aves brasileiras representam, portanto, um investimento seguro no aprimoramento do conhecimento e preservação da biodiversidade do país (Aleixo \& Straube, 2007).

A Área de Proteção Ambiental do Pratigi (APA do Pratigi) foi criada em 02 de abril de 1998, a partir do decreto estadual $\mathrm{n}^{\circ}$ 7.272. Com uma área total de 472.455 $\mathrm{Km} 2$, estende-se por cinco municípios do Baixo Sul da Bahia, três deles integralmente inseridos na sua poligonal (Igrapiúna, Ituberá e Piraí do Norte), e dois deles parcialmente inseridos (Ibirapitanga e Nilo Peçanha) (GONÇALVES, 2014). Integrante no corredor central da Mata Atlântica, torna-se estratégica no sentido da conservação desde bioma, uma vez que comporta, dentro dos seus limites, uma área remanescente de floresta de 35.686 ha, que é um dos principais remanescentes florestais do estado (ROCHA, 2010).

O presente estudo aborda dados acerca da avifauna presente em duas macrorregiões da APA Pratigi, inseridas nas cidades Ibirapitanga e Igrapiúna, referenciados como Ecopolo I e II, respectivamente. Assim, foi realizado um inventariado das espécies presentes nos Ecopolos I e II e que estão depositados no acervo da Coleção de Aves do Museu de Zoologia da Universidade Estadual de Feira de Santana (MZFS). Estima-se que com os presentes dados fornecidos acerca da riqueza, ocorrência e status das espécies, seja possível otimizar o planejamento de expedições de coletas para a região focando as espécies menos coletadas, auxiliando a economizar tempo e recursos financeiros que são empregados em pesquisas científicas promovidas por instituições que as fomentam. 


\section{MATERIAL E MÉTODOS}

Para a produção do presente estudo, foram feitas buscas na Coleção de Aves do Museu de Zoologia da Universidade Estadual de Feira de Santana, tanto em seu acervo físico quanto no banco de dados digitalizado, registrando-se todas os espécimes de todas as espécies coletados nos Ecopolos I e II da APA do Pratigi (Ibirapitanga e Igrapiúna, respectivamente, ambos no estado da Bahia). A nomenclatura e classificação das espécies seguiram as determinações de Piacentini e colaboradores (2016) e a base de dados WikiAves, construído por ornitólogos de todo Brasil, sendo uma das principais referências no campo da Ornitologia devido a facilidade que essa base oferece na obtenção de dados fundamentais acerca da espécie que se deseja obter conhecimentos.

Foi determinada a proporção da composição específica de aves dos Ecopolos I e II da APA do Pratigi tem representação na Coleção de Aves do MZFS a partir dos dados sobre a avifauna destas áreas que foram inventariadas recentemente pela equipe do Laboratório de Ornitologia da Universidade Estadual de Feira de Santana (SETUBAL, 2015). Sobre cada espécie de ave registrada, foi determinado seu endemismo (Sick 1997) e status de ameaça de extinção (Ministério do Meio Ambiente MMA, 2014) caso exista.

\section{RESULTADOS E/OU DISCUSSÃO}

Foram registradas 262 espécies, distribuídas em 55 famílias de aves. A família que obteve maior representatividade foi Tyrannidae (30 espécies), seguida por Thraupidae (26 espécies), Trochilidae (20 espécies), Thamnophilidae (14 espécies) e Furnariidae (nove espécies).

Quanto aos registros de ocorrência das espécies, as mesmas se distribuem pelos Ecopolos I e II do seguinte modo: 184 espécies no Ecopolo I, 220 espécies no Ecopolo II. A família Tyrannidae apresenta-se como a mais representativa em ambos os Ecopolos (Figura 1).

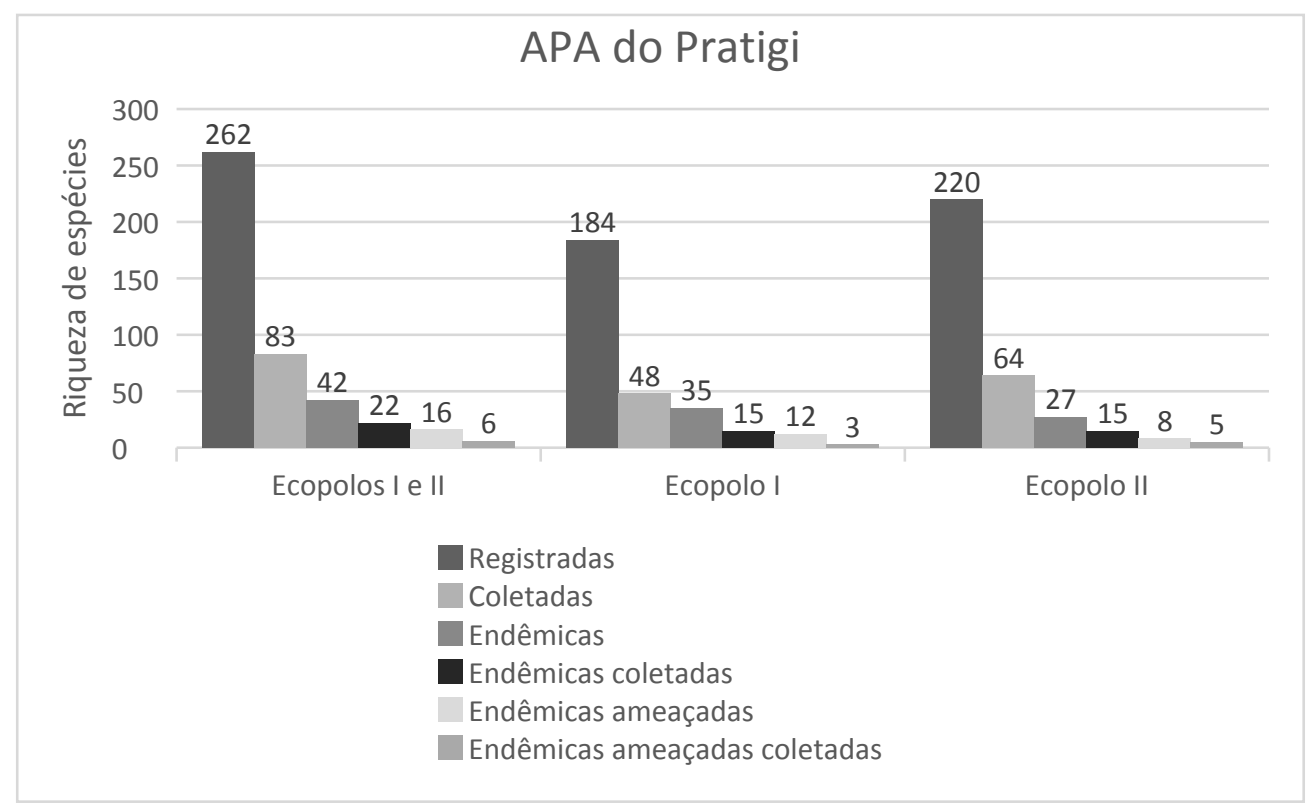

Figura 1: Avifauna dos Ecopolos I e II da Área de Proteção Ambiental do Pratigi, Bahia. Registradas: espécies ocorrentes em campo; Coletadas: espécies presentes no acervo da Coleção do Museu de Zoologia da Universidade Estadual de Feira de Santana; Endêmicas: espécies endêmicas da Mata Atlântica; Ameaçadas: segundo Ministério do Meio Ambiente (2014). 
Houve o registro da ocorrência de 42 espécies endêmicas da Mata Atlântica. Houve também o registro de 28 espécies que indicam algum dos status de ameaça (Ministério do Meio Ambiente, MMA, 2014): quatro espécies constam como Quase Ameaçada, 14 como Vulnerável, sete como Em perigo e três como Criticamente Ameaçada. Dentre as 28 espécies registradas em algum tipo de status de ameaça, 16 são espécies endêmicas da Mata Atlântica, como exemplo Conophaga lineata ou Myrmotherula urosticta. Das 16 espécies endêmicas registradas em algum tipo de status de ameaça, há no acervo da Coleção a presença de 11 espécies coletadas, advindas de doação, já que o curador responsável pela Coleção de Aves do MZFS não possui autorização específica para coletar espécimes ameaçados, fornecida pelo Instituto Chico Mendes de Conservação da Biodiversidade - ICMBio.

Dentre as 262 espécies registradas nos Ecopolos I e II, contabilizou-se que há 83 espécies coletadas e armazenadas no acervo da Coleção de Aves do MZFS. Assim, é possível afirmar que essas 83 espécies representam aproximadamente 31,68\% das espécies ocorridas nos Ecopolos. Portanto, no acervo da Coleção consta 48 (26\%) das espécies coletadas no Ecopolo I e 64 (29\%) de espécies coletadas no Ecopolo II havendo, portanto, maior representação das espécies ocorridas no Ecopolo II.

\section{CONSIDERAÇÕES FINAIS}

O Ecopolo II é a região em que foram registradas mais ocorrências e coletas de espécies. Assim, visando a otimização do manejo de tempo e verbas que são destinados para viagens, em que haverá eventuais coletas, será mais importante que se somem mais esforços de campo na região que compreende o Ecopolo I, uma vez que sua avifauna tem menos ocorrências registradas e coletadas no acervo da Coleção do MZFS.

Thraupidae, Trochilidae e Tyrannidae são as famílias as mais bem representadas nos registros da Coleção do MZFS. Thraupidae apresenta 12 espécies coletadas, sendo a família que contém mais registros de coleta, e Tyrannidae, mesmo tendo sido registrada como a família que mais obteve registros de ocorrências nos Ecopolos I e II, apresenta 8 espécies coletadas. Um dos prováveis motivos que explica por que Tyrannidae apresenta menor quantidade de espécies coletadas é que as redes de neblinas, método usado para captura-las, capturam preferencialmente espécies que habitam o sub-bosque, e como Tyrannidae tem representantes que ocupam todos os extratos de florestas e matas abertas, esse método de captura não obteve tanta eficiência para amostrar essa família, já que o limite de captura do método refletiu na representatividade de espécies coletadas dessa família.

Assim, é importante a diversificação dos métodos de coleta em campo. A rede de neblina é tida como um dos principais instrumentos utilizados, mas amostra, sobretudo, espécies de subbosque. Thamnophilidae apresenta maior quantidade de espécies endêmicas (8 espécies endêmicas registradas), e destas 8 espécies, 5 estão amostradas no acervo da Coleção de Aves do MZFS.

Famílias como Thamnophilidae são pertencentes a regiões tropicais e, dada a localização de onde foram realizadas os registros de ocorrência e as coletas, era esperado que houvesse essa representatividade de espécies endêmicas.

Desta forma, a avifauna da APA do Pratigi está longe de ser suficientemente amostrada na Coleção de Aves da MZFS, sendo que o Ecopolo I deve ser mais intensivamente explorado quanto às coletas, uma vez que, até o momento, é o Ecopolo que apresenta menor quantidade de espécies coletadas, e também por apresentar mais registros de espécies endêmicas, mas menos espécies endêmicas coletadas, se comparadas ao Ecopolo II. 


\section{REFERÊNCIAS BIBLIOGRÁFICAS}

ALEIXO, A. \& STRAUBE F. C Coleções de aves brasileiras: breve histórico, diagnóstico atual e perspectivas para o futuro. Revista Brasileira de Ornitologia 15 (2): $315-324$

Comitê Brasileiro de Registros Ornitológicos (CBRO) (2007) Listas das Aves do Brasil. <http://www.cbro.org.br>.

GONÇALVES, R. S. 2014. História Ambiental da APA do Pratigi-Bahia. UEFS, Feira de Santana, Msc diss.

PIANCENTINI et al. Annotated checklist of the birds of Brazil by the Brazilian Ornithological Records Committee / Lista comentada das aves do Brasil pelo Comite Brasileiro de Registros Ornitologicos. Revista Brasileira de Ornitologia, 23(2): 91-298

ROCHA, R.B. et.al. Caracterização Sócio-Ambiental da Área de Proteção Ambiental do Pratigi. UESC/IFV/OCT. 2010. 39 p.

SETUBAL, M. J. Composição específica e estrutura trófica da avifauna em dua áreas de Mata Atlântica no Baixo Sul da Bahia. UEFS, Feira de Santana, Msc diss.

SICK, H. 1997. Ornitologia brasileira. Rio de Janeiro: Nova Fronteira. 910 p.

SILVEIRA, L. S \& OLMOS, F. 2007 Quantas espécies de aves existem no Brasil? Conceitos de espécie, conservação e o que falta descobrir. Revista Brasileira de Ornitologia 15 (2): 289-296 